\title{
Silent Trades
}

\section{CYNTHIA ARRIEU-KING}

The class hates when in one translation blue night ends in a lily, and in the other a man goes into a bodega.

Their suffering is great when faced with no correct translation.

A few hundred Venn diagrams overlapping nowhere. Always a piece seems missing.

Back in the times of silent trades

if two peoples did not speak a common language

one party left goods in a grassy area, the other waited, got closer, felt how heavy the salt or beef was, or picked the tool they needed, left pieces of gold.

Students start to translate: Some argue the plums in a poem should be plush, others fresh

In a poem, one thing is meant but that thing is meant by the totality of all language, the pure language that no one speaks.

So we are left with a goose flying overhead, but in place of its shadow a mallard swims. 